\title{
ORGANIZAÇÃO SOCIAL BASEADA NA LÓGICA DE CADEIA-REDE PARA POTENCIALIZAR A EXPLORAÇÃO DO AÇAÎ́ NATIVO NA AMAZÔNIA OCIDENTAL BRASILEIRA
}

\author{
SOCIAL ORGANIZATION BASED ON CHAIN-NETWORK \\ LOGIC TO PROMOTE THE EXPLORATION OF NATIVE \\ AÇAÍ IN WESTERN BRAZILIAN AMAZON
}

Recebido: 08/05/2013 Aceite: $02 / 07 / 2013$

Mariluce Paes de Souza ${ }^{1}$ Fabiana Rodrigues Riva ${ }^{2}$ Tania Nunes Silva ${ }^{3}$ Diego Cristovão Alves de Souza Paes ${ }^{4}$

\section{RESUMO}

O presente artigo tem como objetivo apresentar uma proposição de organização na lógica de cadeia e de redes, visando a potencializar a exploração do Açaí Nativo na Amazônia Ocidental Brasileira, descrevendo a cadeia produtiva do Açaí nativo. O estudo, de caráter exploratório, abrange os municípios de Porto Velho, Guajará-Mirim e Machadinho D'Oeste, no estado de Rondônia, destacando-se as comunidades residentes nas áreas de preservação na região do Baixo Rio Madeira, onde foram coletados os dados primários. Como resultado, foi possível depreender que, do Açaí Nativo, derivam-se produtos alimentícios, fármacos e cosméticos para consumo local e exportação. Constatou-se que, além das disponibilidades dos açaizais, a região do Baixo Rio Madeira, em relação aos outros espaços de produção, dispõe de logística de transporte, de mercado consumidor e, ainda, de mais facilidade de interação com os chamados atravessadores. Ao final, faz-se a proposição de um arranjo organizacional para fortalecimento da cadeia produtiva extrativista do açaí nativo, baseada na lógica de cadeia e de redes calcadas em organizações de natureza social, regularização produtiva e comercialização.

Palavras-chave: Açaí Nativo; Cadeia-rede; Organizações sociais; Amazônia.

\footnotetext{
${ }^{1}$ Possui graduação em Administração pela Universidade Federal de Rondônia - UNIR, especialista em Gestão de Recursos Humanos pela Universidade Federal de Santa Catarina - UFSC, mestrado em Engenharia de Produção pela Universidade Federal de Santa Catarina - UFSC, doutorado em Ciências Socioambientais pela Universidade Federal do Pará - UFPA e pós-doutorado em Administração pela Universidade Federal do Rio Grande do Sul - UFRGS. Atualmente é Coordenadora do Centro de Estudos Interdisciplinar em Desenvolvimento Sustentável da Amazônia - CEDSA, professora associada da Universidade Federal de Rondônia, atua na Departamento Acadêmico de Administração na graduação e no Programa de Pós-Graduação Mestrado em Administração. Porto Velho, Rondônia, Brasil. E-mail: mariluce@unir.br.

${ }^{2}$ Possui graduação e mestrado em Administração pela Universidade Federal de Rondônia - UNIR. E-mail: fabianariva@ gmail.com.

${ }^{3}$ Possui graduação em Ciências Contábeis pela Fundação Escola de Comércio Álvares Penteado, mestrado em Administração pela Universidade de São Paulo e doutorado em Sociologia pela Universidade de São Paulo. Atualmente é professora da Universidade Federal do Rio Grande do Sul - UFRGS. Porto Alegre, Rio Grande do Sul, Brasil. E-mail: tnsilva@ea.ufrgs.

${ }^{4}$ Possui graduação em Relações Internacionais pela Pontifícia Universidade Católica de Minas Gerais e mestrado pela Fundação Getúlio Vargas - FGV. Atualmente é doutorando pela Universidade Federal do Rio Grande do Sul - UFRGS. Porto Alegre, Rio Grande do Sul, Brasil. E-mail: diegopaes@gmail.com.
} 


\section{ABSTRACT}

The present paper has the objective to expose a proposition of organization within a chain and network logic, aiming to potentiate the extraction of the Native Açai Berry at the Western Brazilian Amazon rainforest. This exploratory study involves the municipalities of Porto Velho, Guajará-Mirim and Machadinho D'Oeste, at the Brazilian state of Rondônia, with primary data originating mostly from conservation areas at the lower Madeira River region. As a result, it was possible to infer that from the native Açai Berry, derives food, pharmaceuticals and cosmetics, for both local consumption and international markets. It was found that beyond Açai Berry plantations availability, the lower Madeira River provides better transport logistic, consumer market and greater possibility of interaction with middleman than most Açai production areas. As a conclusion, it is made a proposition of an organizational arrangement to strengthen the extrativist productive chain of the Native Açai Berry, based on the network and chain logic, oriented towards an organization based upon social organizations, manufacturing regularization and marketing.

Keywords: Native Açaí Berry; Chain-Network; Social Organizations; Amazon.

\section{INTRODUÇÃO}

Secularmente, várias comunidades da região amazônica, localizadas nos estados de Rondônia, Roraima, Amazonas, Pará, Amapá, Acre, exploram e têm como fonte de subsistência os produtos da floresta, hoje denominados de PFNMs - Produtos Florestais Não Madeiráveis; mas estes também se revestem de grande importância para a economia tradicional local, a regional, e alguns, como é o caso do açaí, até para a nacional. Destacam-se, adicionalmente, o legado cultural, as práticas espirituais, que fornecem elementos para os folclores, além de proporcionar à população das comunidades grande diversidade de recursos, que vão desde produtos alimentares até os próprios para abrigos, proporcionando, ainda, seu uso como remédios para curas de doenças endêmicas.

Embora com esse legado, observa-se que a produção científica publicada sobre a aplicação e manejo do produto ainda não são representativas, dificultando a sua divulgação. Além disso, as comunidades produtoras utilizam o produto no sistema de troca ou escambo, favorecendo a economia informal. Com isso, faz-se necessário que outras análises sejam efetuadas, de forma a visualizar em que mercados tal produção pode ser comercializada, para que seja determinados a forma e o tipo de organização, que podem criar e apropriar valor a esse produto (IAG, 2005).

Isso é importante destacar, uma vez que a comercialização de produtos extrativista não é regulamentada no Brasil, e ainda, em termos de planejamento, coordenação e gestão dos interesses econômicos dos coletores, produtores e exportadores, é desassistido pelas agências governamentais de fomento (PASTORES JÚNIOR e BORGES, 1998). Ou seja, a cadeia produtiva não responde aos sinais do mercado, favorecendo com que os atravessadores determinem o preço de venda, omitindo para os extratores as informações sobre o mercado.

A partir da pesquisa realizada sobre a cadeia produtiva do Açaí Nativo em Rondônia, essa cadeia pode ser classificada como recente e incompleta, apesar dos séculos de extração para subsistência. Poucas são as informações, e, quando existe o acesso, este é incipiente, não sendo aproveitadas as oportunidades, dificultando o crédito e, ainda, a assistência técnica, a inovação tecnológica e a capacitação gerencial das populações locais e pequenos produtores. No entanto, contribui substantivamente para a geração de renda e bem estar de famílias de baixa renda, que funcionam como fornecedoras do açaí, geralmente aos intermediários da cadeia.

Como se pode ver, o extrativismo, além de representar uma significativa fonte de renda para a população que vive no interior da Amazônia, favorece a preservação da floresta, em face 
da extração cuidadosa de seus recursos pela população residente. Trata-se de uma fonte de obtenção de matéria prima que se transforma em produtos oriundos das florestas e, ainda, pode reverter em serviços ambientais socialmente e economicamente sustentáveis.

No que concerne ao ambiente para a inovação, deve-se considerar a premissa básica da economia como estudo dos recursos escassos e sua atribuição. A inovação institucional, científica e tecnológica, nesse contexto, parece ser algo que a sociedade tem como valor e percebe antes que os recursos sejam alocados no processo (SRINIVAS; SUTZ, 2008).

Embora os produtos florestais não madeiráveis sejam pouco significativos no contexto econômico geral, são imprescindíveis para sobrevivência das populações tradicionais e agroextrativistas. Mesmo significando uma renda baixa, esses produtos têm a nobre função de preservar as florestas da Amazônia, possibilitando diversificada fonte alimentar aos seus habitantes, mas detendo potencial de mercado, interno e externo. Pretende-se demonstrar a importância social e econômica do Açaí Nativo e como este pode se organizar em cadeia-rede. Para tanto, formularam-se os seguintes questionamentos: Considerando a cadeia produtiva do açaí nativo na perspectiva de filière, que relações se podem encontrar entre seus atores? Qual organização adequada para potencializar a exploração do Açaí Nativo?

O presente artigo tem como objetivo apresentar uma proposição de organização na lógica de cadeia-rede, visando a potencializar a exploração do Açaí Nativo na Amazônia Ocidental Brasileira. Para isso, descreve-se a cadeia produtiva do açaí nativo. Este trabalho consiste em um estudo exploratório, parte-se de dados oriundos de uma pesquisa sobre vários PFNMs. A pesquisa, oriunda de projeto financiada pelo CNPq, tratava-se de um Casadinho com a UFRGS e foi realizada no ano de 2010, abrangendo os municípios de Porto Velho, principalmente a região do Baixo Rio Madeira, Guajará-Mirim, Machadinho D'Oeste, Ariquemes e Costa Marques, no estado de Rondônia. Utilizou-se a estratégia de coleta em bases de dados disponíveis na SEDAM, EMATER, IBAMA, IBGE, AROM, em prefeituras e outros locais; efetuaram-se entrevistas estruturadas, com uso de formulários, como roteiros e visitas às comunidades. A partir dos dados obtidos $\mathrm{e}$ com base na revisão de literatura, foi possível descrever a cadeia produtiva e proceder a análise, partindo-se dos conceitos de cadeias produtivas pressupostos de filière.

Destaca-se o desenho da cadeia e, a partir da análise, como se encontram as relações interorganizacionais em diversos aspectos, as quais vão desde a falta de organização social para coordenar e conduzir processos de produção até a comercialização. Observa-se, ainda, a falta de políticas públicas de apoio ao empreendedorismo social ou coletivo e de valorização dos PFNMs, dificultando a implementação de ações que visem à consolidação e ao fortalecimento de organizações locais.

O presente artigo se compõe de quatro partes: a introdução; o referencial teórico, as relações organizacionais e redes solidárias; a discussão e análise de resultados; as proposições e considerações.

\section{REFERENCIAL TEÓRICO}

Para nortear este estudo, buscou-se revisar a teoria a fim de obter o entendimento sobre o Produto Açaí Nativo; os Produtos Florestais Não Madeiráveis - PFNMs; o Filière; as Redes e Organizações Sustentáveis.

Considerando a natureza da pesquisa e sua relação com o meio natural, destaca-se a definição de sustentabilidade, recorrendo a Ehlers (1996), que se refere ao uso dos recursos biofísicos, econômicos e sociais segundo sua capacidade, em um espaço geográfico, para obter bens e serviços diretos e indiretos da agricultura e dos recursos naturais, com intuito de satisfazer as ne- 
cessidades das gerações atuais e futuras. $O$ valor presente dos bens e serviços deve representar mais que o valor das externalidades e dos insumos incorporados, melhorando ou, pelo menos, mantendo de forma indefinida a produtividade do ambiente biofísico e social. Além disso, o valor presente deve estar equitativamente distribuído entre os participantes do processo.

\subsection{A Euterpe Olerácea}

O açaizeiro é uma palmeira que recebe o nome científico de Euterpe Olerácea e pertence à ordem dos Arecales, gênero Euterpe da família Palmae. É uma palmeira nativa da Amazônia, concentrando-se nas áreas de várzeas e planas, em baixadas de formação recente às margens dos Rios Madeira, Amazonas e afluentes, conhecidas como várzeas: alta, baixa e igapó.

Para Poullet (1998), o açaí é um produto importante na dieta alimentar e cultural da população da Amazônia. No entanto, Rogez (2000) contribui dizendo que o açaizeiro é uma palmeira das mais produtivas do ecossistema que abriga a população tradicional da Amazônia, pois, além de ser um alimento muito nutritivo, pode fornecer matéria prima para remédios, corantes, artesanatos e, ainda, se extirpada, prover até madeira para construções rurais, palha para coberturas, e outros. Como fonte de alimentos, oferece o fruto, do qual é extraído o suco ou vinho do açaí, como é conhecido na Amazônia. É em função desta múltipla utilidade que o açaí tem importante papel para as populações tradicionais da Amazônia.

Comumente, são comercializados dois tipos de frutos do açaizeiro. O preto pode ser encontrado nos solos úmidos, conhecidos na Amazônia como igapós e várzeas, áreas invadidas pelas águas dos rios. Para Nogueira et al. (1995), o açaizeiro é muito versátil e sobrevive nos solos pouco aerados graças às raízes adaptadas, e Rogez (2000) complementa dizendo que a palmeira absorve os minerais necessários devido ao número de raízes que processam um grande volume de terra. Com coloração arroxeada, é o mais comum e o mais consumido. É mais resistente ao ataque de pragas. $\mathrm{O}$ açaí Branco tem coloração verde quando maduro e é menos conhecido, apresenta pequena diferença de sabor e tem grande procura no mercado. Rogez (2000) supõe se tratar de albinismo, uma vez que o cultivo da variedade não é possível por produtores.

Os frutos surgem após o terceiro ano de plantio, quando as inflorescências, chamadas de espádice, crescem da base da bainha das folhas, as quais surgem após a queda da folha, abaixo da região colunar, no que a população ribeirinha chama de "axila" das folhas; e, com o amadurecimento dos frutos, a angulação da espádice altera em relação ao tronco, nesse estágio, esta é denominada de cacho, também chamado de vassoura pelos coletores. Em média, cada planta produz de três a oito inflorescências, cada uma dá origem a um cacho com centenas de frutos, os quais pesam, em média, 4 kg (FÚRIA, 1993; ROGEZ, 2000).

$\mathrm{O}$ açaizeiro é uma árvore que pode chegar a atingir até 30 metros de altura e que prefere áreas úmidas, fato que faz com que cresça nas margens dos rios. O Brasil é o grande produtor mundial de açaí, responsável por $85 \%$ da oferta mundial (NOGUEIRA, 2006). O interesse pela implementação da produção de frutos tem se dado pelo fato do açaí, antes destinado totalmente ao consumo local, ter conquistado novos mercados e se tornado em importante fonte de renda e de emprego (NOGUEIRA, 2006). A demanda pelo açaí fora da região vem aumentando, principalmente nos Estados do Rio de Janeiro, São Paulo, Brasília, Goiás e na Região Nordeste. No Rio de Janeiro, o açaí é oferecido nas praias e muito popular entre os adeptos da "cultura da saúde" e entre os frequentadores de academias. 
Shanley, Pierce e Larird (2005) classificam os PFNMs como recursos biológicos provenientes de florestas nativas, sistemas agroflorestais e plantações, e incluem plantas medicinais e de uso alimentício, frutas, castanhas, resinas, látex, óleos essenciais, fibras, forragem, fungos, fauna e madeira para fabricação de artesanato.

A extração de produtos não madeireiros é uma atividade fundamental para os moradores da região, que valorizam a floresta por preservá-la em pé, pois a exploração madeireira contribui para a erosão genética das espécies de maior valor comercial, o que compromete o aproveitamento futuro, posicionam-se Souza e Silva (2002). Fiedler, Soares e Silva (2008) afirmam que, nos últimos anos, houve um crescente interesse pelos PFNMs. Há um entendimento melhor sobre a economia das florestas naturais e seus recursos biológicos, e em função, disso estas vêm assumindo papel de destaque, pois se apresentam como fonte alternativa de renda e como potencial de incentivo econômico para frear a devastação das florestas.

Pode-se dizer que o sistema econômico vigente na região amazônica não valoriza a diversidade dos inúmeros ecossistemas, uma vez que a Amazônia tem sido considerada nos planos governamentais do Brasil como um sistema natural, homogêneo. Gama (2005) aponta as dificuldades de acesso às áreas dos PFNMs sendo um dos principais entraves para a retirada a granel desses produtos da floresta. May e Motta (1994) alertam para realidades semelhantes e destacam que um PFNM, para ser comercializado, precisa apresentar alto valor agregado, e isso está relacionado a uma estratégia de desenvolvimento sustentável para o local onde ocorre a extração.

Quanto à estratégia de industrialização, depreende-se, a partir de Pastore Júnior e Borges (1998), que agregar valor aos produtos e criar fontes de trabalho permite a retenção de valor do PFNM no país. Porém, no caso dessa cadeia produtiva no Brasil, o processamento final é pouco praticado, o que é atribuído à falta de tecnologia, mão de obra qualificada e, ainda, à falta de direcionamento de políticas públicas para o setor.

A análise de filière permite, para produtos convencionais, essa articulação entre as características técnicas de um produto ou de processos operacionais e as análises econômicas e estratégias, percorrendo-se os vários elos de uma cadeia que vai desde os insumos e a produção até chegar ao consumidor. A Cadeia Produtiva de Extrativista será usada para compreender a filière do açaí, analisada no presente artigo, pois permite a compreensão da filière, articulando os diferentes elos no seu contexto específico.

\subsection{Análise de Filière}

A análise de filière pode promover uma visão global do sistema de produção e das suas relações, evidenciando as articulações entre os agentes privados e o poder público, bem como os desejos e necessidades dos consumidores dos produtos finais da cadeia.

Recorrendo-se ao entendimento de cadeias produtivas convencionais, vê-se que Morvan (1985) apud Zylbersztajn, (1995) define cadeia produtiva como sendo uma sequência de atividades que conduzem à produção de bens. Sua articulação é fortemente influenciada pelas possibilidades tecnológicas e é definida pelas estratégias dos agentes que buscam a maximização de seus retornos. As relações existentes entre os agentes são de interdependência ou complementaridade e são determinadas por forças hierárquicas. Considerando que, em diferentes níveis de análise, a cadeia é um sistema mais ou menos capaz de assegurar sua própria transformação, verifica-se que Batalha (1997, p. 26) e Zylbersztajn (1995) tratam a análise de filiére como 
sendo também análise de cadeias de produção. Dessa forma, a partir do entendimento desses autores, pode-se dizer que filière é uma ferramenta utilizada para descrever as relações do interior da cadeia de produção, desde o fornecimento de matéria prima (produção) até o consumidor final. No presente artigo, os termos filière e cadeia de produção serão usados indistintamente.

O surgimento da noção de filière, na década de 1960, na França, parte do reconhecimento que, no decorrer da produção de um determinado produto, ocorrem diversas relações entre agentes econômicos situados em diferentes estágios da cadeia de produção. Essas relações auxiliam na descrição e explicação da estrutura e do funcionamento de uma atividade econômica (CARVALHO JÚNIOR, 1995).

De acordo com Labonne (1985), a noção de filière divide o sistema de produção em três subsistemas: 1) produção - compreende as entradas e saídas na indústria e na produção agrícola; 2) transferência - refere-se à transformação industrial; e 3) armazenamento e consumo - viabilizam o consumo e o comércio dos produtos finais. O subsistema de transferência é considerado o setor mais heterogêneo, pela complexidade das funções (processamento, distribuição, transporte), com a utilização de técnicas tradicionais até às mais sofisticadas e modernas.

Importante destacar que cada filière concentra uma pluralidade de atores, de estratégias e de dinâmicas que produzem uma diversidade de dispositivos e de formas de regulação, as quais são coordenadas pelas grandes firmas, cujos objetivos são a competitividade e a geração de lucros. A presença de dominação e subordinação no interior das filières provoca desigualdades quanto à participação na divisão do produto social. Dessa forma, a subordinação é acompanhada por uma participação em menor grau ou mesmo pela pobreza, o que leva à ideia de que, em uma economia fundada na competitividade, o não competitivo é excluído, ou seja, a massa de produtores e de consumidores considerados não competitivos (FÀVERO, 1996).

\subsection{Cadeias Produtivas Solidárias e Organizações Sustentáveis}

Partindo da análise de filière e considerando as características da região Amazônica, das comunidades e dos PFNMs, pode-se visualizar a possibilidade de fomentar uma Cadeia Produtiva Solidária (CPS) que consiste em uma articulação em rede. Esta se compõe de um conjunto de Empreendimentos Econômicos Solidários (EES) que se organizam em torno da elaboração de um produto final, envolvendo a produção de seus insumos e serviços. As várias etapas necessárias para a transformação do produto, que envolve produção, distribuição e comercialização, são realizadas por empreendimentos econômicos solidários.

Os empreendimentos partem das organizações sociais, associações e cooperativas e operam de acordo com os princípios da economia solidária, de maneira democrática e justa, tanto na organização interna quanto no relacionamento interorganizacional. Após a comercialização desses bens ou serviços, obtém-se um valor excedente. Nos empreendimentos solidários, esta riqueza gerada é repartida na medida em que as pessoas podem comprar os produtos ou serviços das redes em cadeias produtivas (METELLO, 2007).

Além das relações econômicas, os empreendimentos participantes da CPS devem manter uma relação de solidariedade entre si, buscando o desenvolvimento de todos os elos. Essa lógica da ajuda mútua é importante para a sobrevivência da Cadeia Produtiva Solidária. Mance (2003) afirma que as cadeias produtivas solidárias podem ser formadas com EES já operantes ou existentes a partir do aquecimento da cadeia, por demanda interna, em que os empreendimentos atuam de forma a se complementarem, remetendo ao conceito de redes.

Lowe, Murdoch, Ward (1995) dizem que Redes de Desenvolvimento Rural são proces- 
sos de mudança rural, então, não devem ser vistos como determinados unicamente pelas forças presentes na globalização do sistema alimentar e que seu estudo deve incluir os processos de reestruturação rural, que envolvem as dinâmicas sociais e econômicas regionais. Nesse sentido, Lowe, Murdoch e War (1995) propõem uma noção de rede em que se dá ênfase à necessidade de relacionar duas dimensões, a espacial e a social, sempre levando em consideração as relações de poder. Os autores dizem, ainda, que as relações sociais entre os agentes locais e não locais seriam mais importantes que pertencer ou não a um dado território. A partir dessa discussão, é notável que exista uma preocupação de como identificar, e assim caracterizar, um tipo de rede e o ambiente de relações que ali estão envolvidas.

Aprofundando o conceito sobre a utilização de rede, Amato Neto (2000) salienta não mais uma visão geral do que se trata rede, e sim do nível mais intermediário da rede. Segundo ele, esse é o nível que se tem contato direto com a agricultura, configurando, então, determinados padrões de articulações dos atores locais e não locais em processo de desenvolvimento.

As estratégias de desenvolvimento rural são pensadas a partir do fortalecimento das atividades agricolas e não agricolas. Geralmente, as regiões de sucesso devem ter uma maneira de agregar inovação aos elementos socias e naturais. A ênfase na inovação indica que as associações ou redes mais apropriadas não são apenas amálgamas de arranjos institucionais pré-existentes, mas sim aquelas que habilitam novas formas de orquestrar o desenvolvimento econômico.

Foi partindo dessas perspectivas teóricas que o estudo da cadeia produtiva do açaí nativo foi orientado, tanto para sua descrição como para a apresentação de proposições, visando à melhoria da exploração local.

\section{MÉTODO DE PESQUISA}

A pesquisa ocorreu a partir da teoria para o campo empírico e com procedimento de análise de retorno do campo para a teoria, obedecendo à perspectiva analítico-descritiva. A coleta de dados secundários teve como fontes os banco de dados oficiais, dados gerados pelo Plano Agropecuário e pela Florestal de Rondônia, IBGE, IBAMA, SEDAM, ICMBio, e outras instituições governamentais e não governamentais.

Quanto aos dados primários, foram estruturados seis formulários com questões abertas e fechadas, direcionadas aos diversos segmentos da cadeia: extrativistas, intermediários, indústria, varejo, organizações e consumo. Além das entrevistas, a pesquisa de campo incluiu visitas às comunidades e propriedades. Os municípios pesquisados foram: Ariquemes, Porto Velho, Ji -Paraná, Guajará-Mirim, Machadinho D’Oeste e Costa Marques. No entanto, foi no Município de Porto Velho, região do Baixo Rio Madeira, onde se encontra a exploração do açaí nativo, que foi organizada uma expedição de barco, com duração de quatro dias e com visitas a oito comunidades no mês de fevereiro de 2010.

Para estudar a viabilidade desse produto, abrangeu-se toda a cadeia produtiva, envolvendo os segmentos da coleta e produção, do processamento, armazenamento, transporte, comercialização e consumo, inserindo-se o contexto do ambiente organizacional com avaliação do emprego de mão de obra qualificada, das condições de remuneração e da legislação, para entender o funcionamento da filière e como o valor agregado pode ser alcançado. 


\section{DISCUSSÃO E ANÁLISE DE DADOS}

\subsection{Descrição da Cadeia Produtiva Extrativista do Açaí Nativo}

A cadeia produtiva extrativista do açaí nativo é constituída por diversos segmentos, dentre eles, as chamadas áreas de produção, nas quais estão localizadas as florestas, as áreas da união, as indígenas e as privadas. Estas cadeias produtivas abrangem fornecedores de insumos, coletores, intermediários, indústria de transformação, comércio, consumidor e estão inseridas em um ambiente institucional. Sendo tais cadeias regidas pelas leis de mercado mesmo em situação desfavorável, desenvolvendo suas funções e relações comerciais, que considera o fluxo de capital, as transações que implicam custos, parcerias, bem como todas as outras atividades típicas de uma cadeia produtiva.

A cadeia produtiva do açaí em Rondônia apresenta vários gargalos, situações que dificultam a produção e a inserção de novos empreendimentos. Uma das dificuldades está relacionada ao espaço geográfico da região, em função da localização, da distância, do transporte, da organização social e comercial: a falta de gerenciamento ou mesmo a pouca habilidade na gestão com uso de novas tecnologias.

As potencialidades dos frutos do açaizeiro são diversas, é possível extrair o vinho e a polpa. Com o açaí, são fabricados sorvetes, licores, doces, néctares e geleias, podendo ser aproveitado, também, para a extração de corantes e antocianina. Do caroço, podem ser produzidos carvão, mudas, combustíveis e matéria prima para a indústria automobilística; dos resíduos do caroço, podem ser produzidos etanol, fertilizantes, farelo e adubos, conforme Figura 1, a seguir.

A presença de associações e cooperativas como formas de organização coletiva auxilia no desenvolvimento das cadeias produtivas, aumentando a capacidade de organização e de gestão, para garantir a sustentabilidade e a equidade nas relações.

Figura 1 - Desenho da Cadeia Produtiva Extrativista do Açaí Nativo

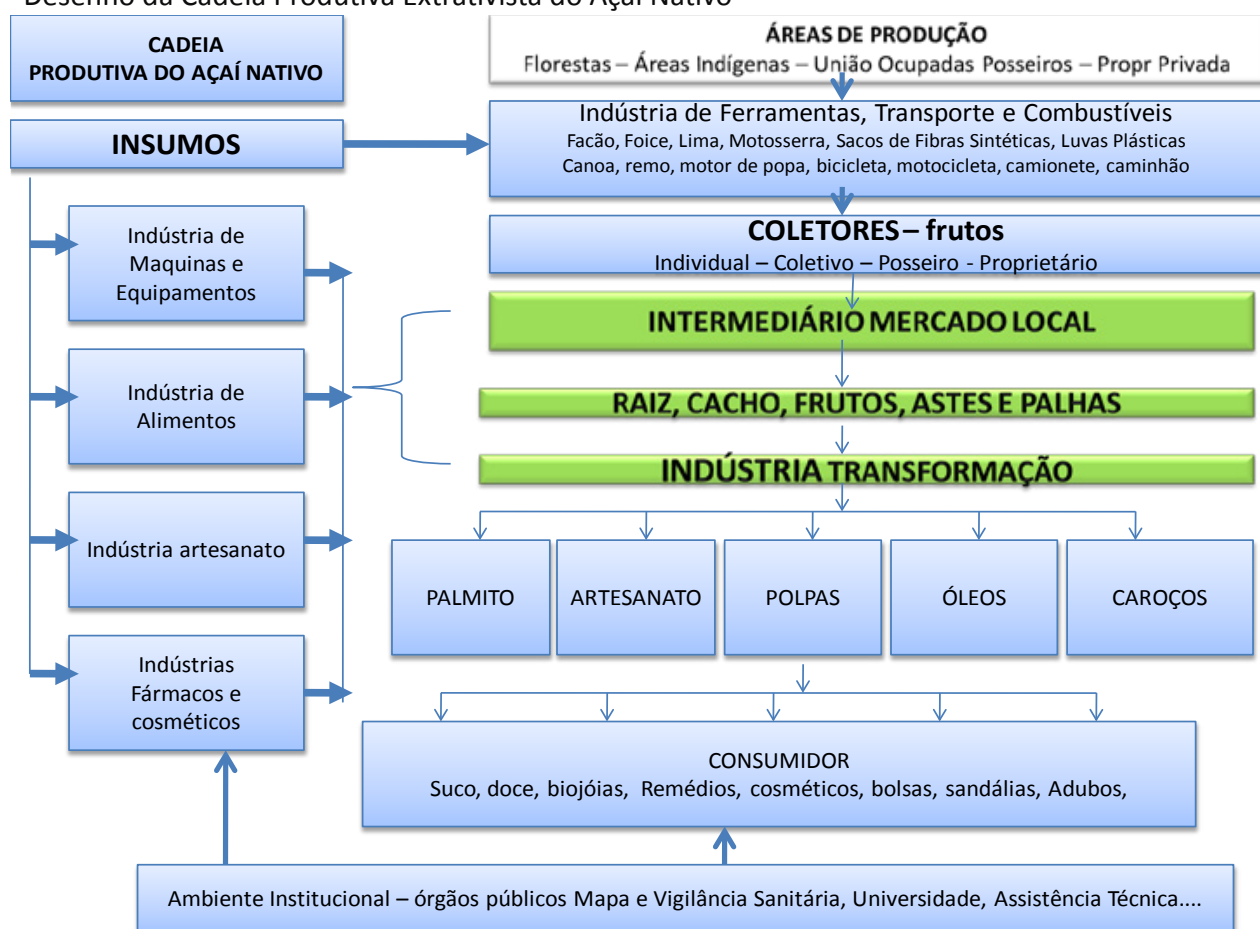

Fonte: Pesquisa de Campo (2010) 
Na região Amazônica, o ambiente institucional tem regras que regem a produção, extração e comercialização de produtos, mas essas políticas não têm sido efetivas e são atribuídas pelo IAG (2005) às deficiências dos movimentos sociais nas articulações em relação ao mercado. $O$ mesmo documento chama atenção para fatores relacionados às questões legais fundiárias: crédito, assistência técnica, acesso a mercados, comercialização, gestão e administração, acesso a mercados, comércio, e marketing afetam o desenvolvimento pleno dos negócios e das cadeias produtivas.

Para Bista e Webb (2006), é possível que a presença de instituições voltadas à melhoria dos meios de subsistência possa estimular a instalação de estruturas de beneficiamento, podendo ter como estratégia a criação de condições que gerem novos conhecimentos a partir de experiências de outras regiões, fomentando a organização coletiva voltada à sustentabilidade de produtos florestais não madeireiros.

Conforme relato dos produtores, confirma-se o que foi mencionado por Fàvero (1996), a subordinação e a dominação dos menos competitivos, provocando desigualdades e exploração. Observou-se que os produtores estão desarticulados quanto à organização social, embora sejam inúmeras as associações, são embrionárias as iniciativas de cooperativas na região, para coordenar e organizar o processo de produção, transferência e comercialização, o que deixa os produtores mais vulneráveis. Os problemas expostos pelos produtores reforçam a falta de políticas públicas de apoio e valorização da produção dos PFNMs, por meio de financiamentos de novas tecnologias, colocando os pequenos produtores em condições de competitividade e de falta de apoio ao empreendedorismo coletivo e social, visando à consolidação e ao fortalecimento de organizações locais (cooperativas, associações, empresas sociais, ONGs);

\subsection{O Desenvolvimento Sustentável da Filiére do Açaí Nativo}

Em se tratando dos PFNMs, o ambiente para a inovação deve considerar a premissa básica da economia como estudo dos recursos escassos e sua atribuição. A inovação institucional, científica e tecnológica, nesse contexto, parece ser algo que a sociedade tem como valor e percebe antes que os recursos sejam alocados no processo (SRINIVAS; SUTZ, 2008).

Avaliando os dados apresentados na Figura 2, a qual demonstra um comparativo entre quatro variáveis: declaração de exploração, valor em reais médio explorado, quantidade total explorada, dados da pesquisa, e crescimento de extração mensurado pelo IBGE, observa-se que a filiére do açaí apresenta significativa diferença em relação a outros PFNMs como: a castanha da Amazônia, cipó titica, látex, copaíba e babaçu.

Os resultados observados na Figura 2 demonstram que somente $12 \%$ dos entrevistados declararam explorar o açaí; contra $40 \%$ que exploram castanha; e $28 \%$, látex, embora os coletores sejam em menor número, verifica-se que a quantidade total explorada e o valor médio obtido com o produto são significativamente superiores. Isso demonstra a expressiva superioridade do açaí frente a outros importantes PFNMS, no entanto, o crescimento de extração apontado pelo IBGE no período de 2006 a 2009 mostra que o açaí cresceu mais de $700 \%$ em quatro anos. Entende-se que essa é uma posição diferenciada de um produto nativo, que fornece matéria prima a partir de um recurso renovável e que precisa ser melhor valorizado. 
Figura 2 - Posição diferenciada do produto açaí nativo

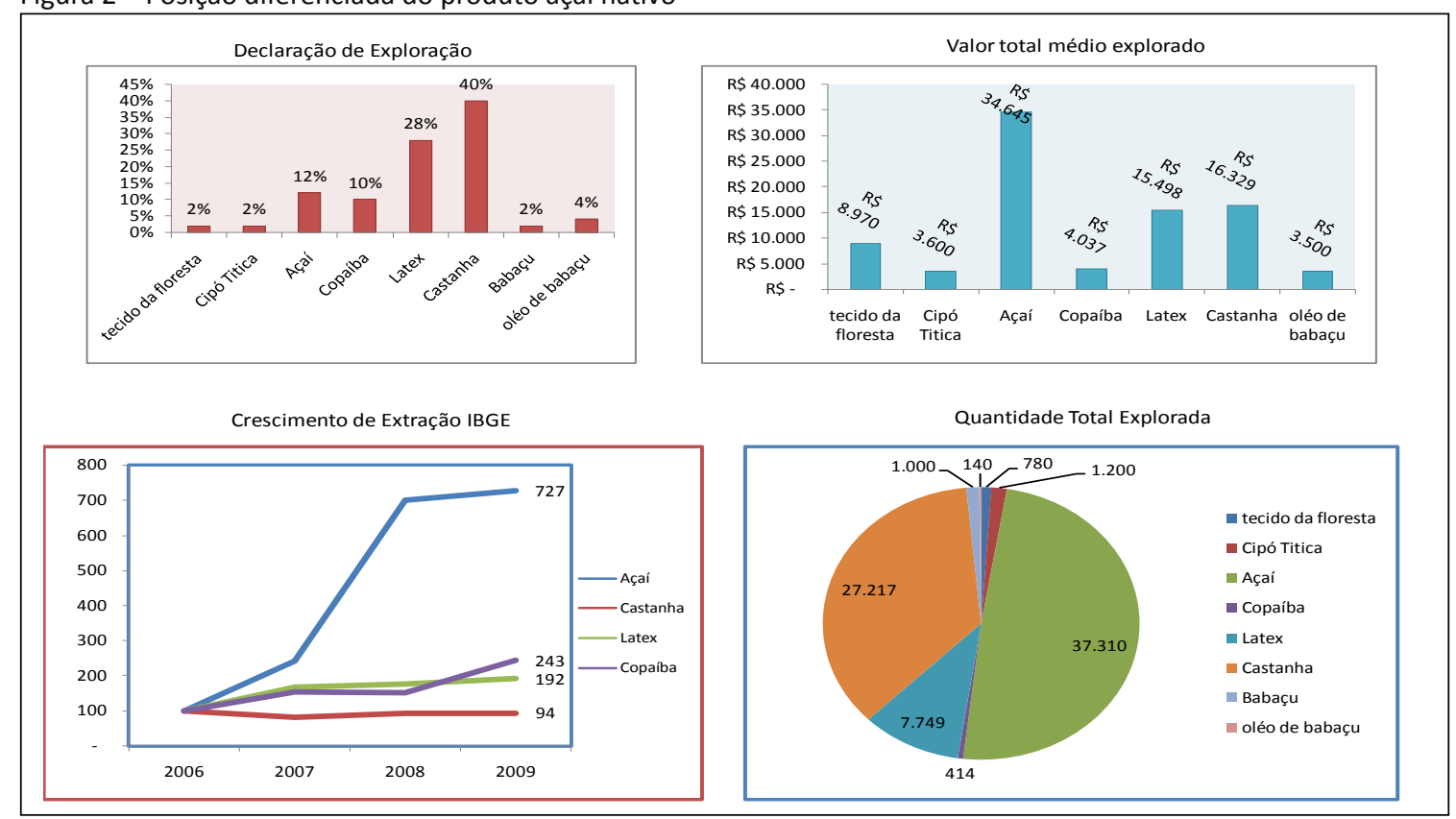

Fonte: Pesquisa de Campo (2010)

A matéria prima existe como está demonstrado na Figura 2, mas os produtores não têm conhecimentos e recursos necessários para o beneficiamento. Segundo relato dos produtores, os problemas enfrentados são muitos, vão das questões relacionadas à legalização da terra ao conhecimento sobre gestão; do acesso a mercados e comércio e marketing à falta de infraestrutura de extração; da disponibilização de escolas ao direito a saúde. O custo do transporte, muitas vezes, é maior do que o preço da venda do produto.

Segundo Yunus; Moingeon; Lehmann-Ortega (2010), as empresas sociais são uma alternativa viável para integrar as organizações sociais voltadas ao bem estar comunitário. Nesse sentido, podem-se inserir as cooperativas, já existentes, como se pode observar a seguir, configurando-se numa rede de empreendimentos comunitários que são capazes de potencializar a produção local com o mínimo de agregação de valor ao produto do açaí nativo. No entanto, para garantir a sustentabilidade do negócio social, o apoio governamental e da iniciativa privada, e o engajamento dos diversos stakeholders parecem ser fatores fundamentais, pois permitem formação e reprodução de significados, entendimentos compartilhados, e redução de riscos.

\subsection{Proposição de Organização Baseada na Lógica de Cadeia-Rede}

Propõe-se fomentar um arranjo produtivo extrativista com a criação de uma Rede de Empreendimentos Comunitários, composta por todos os empreendimentos solidários, como associações de produtores e coletores, pescadores, cooperativas e grupos de trabalhos, pois estes precisam de alternativas para melhores meios de produção, transporte e comercialização de seus produtos e, ainda, para desenvolver competências em organização social, convívio comunitário e solidário.

A Rede de Empreendimentos Comunitários visa a favorecer a descentralização e o compartilhamento das decisões entre os gestores da cooperativa e das associações quando todos se beneficiariam da sinergia gerada pelas relações produtivas e comerciais intraorganizações, como pela possibilidade de obter apoio de stakeholders privados e públicos. Entende-se que, para ob- 
ter a sinergia por parte dos empreendimentos, faz-se necessário estabelecer alguns critérios que garantam a sustentabilidade da Rede por meio de mecanismos de gestão como governança. $O$ processo de articulação pode se tornar difícil, pela falta de comprometimento e sustentabilidade dos atores envolvidos, ocasionando desconfiança e desarticulação da Rede. A criação de um Conselho que possa exercer a governança da Cadeia-Rede, que pode ser denominada de Conselho de Organizações Públicas e Privada de Empreendimentos Ribeirinhos Associados - COOPERA. Sabe-se que o estímulo ao desenvolvimento não é papel meramente do governo ou das autoridades locais instituídas, mas sim de todos os atores envolvidos, como, por exemplo: instituições públicas e privadas, organismos não governamentais, cidadãos, terceiro setor, e outros.

As políticas de governança devem estabelecer os critérios a serem estabelecidos, os quais fortalecerão as relações da Rede e as interações dos mecanismos de desenvolvimento existentes na região. Governança para EURADA $(2003$, p.1) consiste na habilidade de todos os atores da Rede de concordarem a respeito de uma única visão, para o desenvolvimento em que suas habilidades e empreendimentos compartilhem os investimentos, finanças e recursos humanos, para realizar alcance de seus objetivos.

O Conselho proposto no exercício da coordenação - governança da Rede - também pode ser considerado como um processo contínuo, pelo qual os conflitos estão regulados e a cooperação pode ser resolvida. O processo de coordenação compreende a constituição de conseIho formal, capaz de reforçar as relações interorganizacionais e compreender acordos informais que empreendimentos e instituições estabelecem na proteção de seus interesses (OUR GLOBAL NEIGHBOURHOOD apud MILANI, 1999, p.102).

\section{CONCLUSÕES}

A escassez percebida dos diferentes tipos de recursos para a produção, comercialização e distribuição do produto açaí nativo e dos demais PFNMs deve ser combatida, pois se trata de um obstáculo para a inovação e o desenvolvimento, podendo inibir a criatividade e a aprendizagem, levando os trabalhadores a se tornarem incapazes para o uso do conhecimento existente e impossibilitados de enfrentar as necessidades e abordar os problemas de forma diferente. Por isso, entende-se que esse setor merece de atenção; que devem ser criadas políticas públicas direcionadas às necessidades da região; e que é preciso fomentar a proposição de criação de rede de empreendimentos comunitários, visando à integração e à superação das dificuldades como um mecanismo em busca de soluções. 


\section{REFERÊNCIAS}

AMATO NETO, J. , Redes de cooperação produtiva e clusters regionais: oportunidade para as pequenas e médias empresas. São Paulo: Atlas, 2000.

BATALHA, M. O. Sistemas Agroindustriais: definições e correntes metodológicas. In: BATALHA, Mário Otávio (Coord.). Gestão Agroindustrial: GEPAl: Grupo de Estudos e pesquisas agroindustriais. São Paulo: Atlas. 1997.

BISTA, S.; WEBB, E. L. Collection and marketing of non-timber forest products in the far western hills of Nepal. Environmental Conservation, vol. 33, p. 244-255, 2006. Foundation for Environmental Conservation.

CARVALHO JÚNIOR, Luiz Carlos de. A noção de filière: um instrumento para a análise das estratégias das empresas. Textos de Economia, Florianópolis - SC, v. 6, n. 1, p. 109-116, 1995.

EHLERS, E. M. Agricultura Sustentável: origens e perspectivas de um novo paradigma. São Paulo: Livros da Terra, 1996, 178p.

FÀVERO, Celso Antonio. O Mercosul e a Reestruturação da Agricultura: as "Filières" de cereais e a exclusão social. Cadernos de Ciência \& Tecnologia, Brasília, v.13, n.3, p.279302, 1996. Disponível em: <http://webnotes. sct.embrapa.br/pdf/cct/v13/cc13n302.pdf> Acesso em: 31 jan. 2011.

FIEDLER, N. C.; SOARES, T. S.; SILVA, G. F.. Extração de produtos florestais não madeireiros: Importância e manejo sustentável da floresta. Revista Ciências Exatas e Naturais, Vol.10, no. 2, Jul/Dez 2008.

FÚRIA L. R. R. Características e usos do Açaí (Euterpe Olerácea). In (org.), Encontro Sobre Produção de Palmito. Piracicaba-SP, 1993.

GAMA, M. M. B. Principais relações de comercialização de produtos florestais não madeireiros (PFNM) na Amazônia. 2005.
Disponível em: <http://www.agronline.com. br/artigos/artigo. php?id=299>. Acesso em: 08 de Fev. de 2011.

IAG - Grupo de Assessoria Internacional. Programa Piloto para a Proteção das Florestas Tropicais do Brasil (2005). Disponível em: <http://www.socioambiental.org/nsa/doc/ pdf> Acesso em: 4 fev. 2011.

LABONNE, Michel. Sur lê concept de filière en economie agro-alimentaire, 1985.

LOWE, P.; MURDOCH, J.; WARD, N. Networks in Rural Development: Beyond exogenous and endogenous models. Centre for Rural Economy - University of Newcastle upon Tyne, 1995.

MANCE, Euclides André. Como organizar redes solidárias - Rio de Janeiro: DP\&A, 2003

MAY, P. H.; MOTTA, R. S. Valorando a Natureza: Análise Econômica para o Desenvolvimento Sustentável. Rio de Janeiro: Editora Campus, 1994.

METELLO, Daniela Gomes. Os benefícios da associação em cadeias produtivas solidárias: o caso da Justa Trama - Cadeia Solidária do Algodão Agroecológico. Rio de Janeiro: 2007.

NOGUEIRA, O. L. et al. A Cultura do Açaí. Coleção Plantar, Série Vermelha fruteiras EMBRAPA-CPATU-SPI. Brasília DF: 1995.

NOGUEIRA, O. L. Sistema de produção do Açaí. Embrapa Amazônia Oriental. Sistemas de Produção, 4 - 2a Edição, Versão Eletrônica Dez./2006. Disponível em: <http:// sistemasdeproducao.cnptia.embrapa.br/ FontesHTML/Acai/SistemaProducaoAcai_2ed/ paginas/intro.htm> Acesso em: 18 mar. 2011.

PAS (2006). Plano Amazônia Sustentável. Disponível em: <http://www.mma.gov.br/ estruturas/sca/arquivos/pas.pdf > Acesso em: 15 mar. 2011.

PASTORE JUNIOR, F.; BORGES, V. Produtos florestais não madeireiros: processamento, 
coleta e comercialização. Brasília: ITTO/ FUNATURA /UnB /IBAMA, 1998.

POULLET, D. Açaí: Estudo da Cadeia Produtiva. 1 ed. : IEPA-GEA, 1998.

ROGEZ, H. Açaí: Preparo, Composição e Melhoramento da Conservação. 1 ed. BelémPará: EDUFPA, 2000.

SHANLEY, P.; PIERCE, A.; LARIRD, S. Além da Madeira: certificação de produtos florestais não madeireiros. Bogor, Indonésia: Centro de Pesquisa Florestal Internacional (CIFOR), 2005. $153 \mathrm{p}$.

SOUZA, L.A.G.; SILVA, M.F. Bioeconomical potential of Leguminosae from the Negro river, Amazon, Brasil. Proceedings of Conservación de biodiversidad em los Andes yla Amazonia. Inka, 2002, Cuzco, 2002, p. 529-538.

SRINIVAS, S.; SUTZ, J. Developing countries and innovation: Searching for a new analytical approach. Technology in Society, vol. 30 (2008) p. 129-140.

YUNUS, M.; MOINGEON, B.; LEHMANNORTEGA, L. Building Social Business Models: Lessons from the Grameen Experience. Long Range Planning, Vol. 43, 2010, pg. 308 a 325.

ZYLBERSZTAJN, Décio. Estruturas de Governança e Coordenação do Agribusiness: Uma Aplicação da Nova economia das Instituições. Tese Livre Docente, São Paulo: USP, 1995. Disponível em: <http://www.erudito.fea.usp.br/PortalFEA/ Repositorio/616/Documentos.pdf> Acesso em: 02 mar. 2011. 
